\title{
PENGARUH KOMPENSASI DAN KOMPETENSI TERHADAP KOMITMEN ORGANISASI SERTA IMPLIKASINYA PADA KINERJA TENAGA AHLI PERUSAHAAN JASA KONSTRUKSI DI PROVINSI JAMBI
}

Fakhrul Rozi Yamali ${ }^{1}$

\begin{abstract}
The purpose of this research is to find out and analyze the effect of compensation and competency of either partially or jointly towards organizational commitment. Then the influence of the compensation, competence and commitment of the Organization partially or jointly on performance experts. The population in this study of 1,321 people construction services company experts in the province of Jambi. The methods used in this research is a descriptive survey method and sample survey of eksplanatori with the spread as much as 265 respondents. Based on the results of the hypothesis, compensation and competency as well as partially positive and significanteffect together toward organizational commitment (KO) and $R 2=0.53$ or account for $53 \%$, and partially compensation effect positive and insignificant against the performance experts (KA), competence and commitment of the Organization of the partially positive and significant effect on performance experts (KA) while the compensation, competence and commitment of the Organization in together the positive and significant effect on performance experts $(K A)$ and $R 2=0.52$ or account for $52 \%$

Keywords: Compensation, Organizational Commitment, Competence, Performance Experts
\end{abstract}

\section{PENDAHULUAN}

Pembangunan infrastruktur merupakan salah satu pilar pendorong dalam peningkatan daya saing Indonesia dan memiliki multiplier effect yang signifikan bagi ekonomi masyarakat. Salah satu bagian usaha yang mengalami perkembangan dalam pembangunan infrastruktur adalah usaha jasa konstruksi. Mengacu kepada UU No. 18 Tahun 1999 tentang jasa konstruksi yang dimaksud dengan jasa konstruksi adalah layanan jasa konsultansi perencanaan pekerjaan konstruksi, layanan jasa pelaksanaan pekerjaan konstruksi, dan layanan jasa konsultansi pengawasan pekerjaan konstruksi. Setiap Provinsi di Indonesia tak terkecuali di Provinsi Jambi, pertumbuhan sektor jasa konstruksi mengalami peningkatan dibandingkan sektor-sektor penopang pertumbuhan ekonomi yang lain.

Menurut Awadh and Saad (2013: 64) dalam penelitiaannya bahwa "The employee performance would be considered as backbone organization as it leads to its development effectively”. Bahwa kinerja pegawai sebagai tulang punggung dalam pengembangan organisasi secara effektif. Berdasarkan pernyataan tersebut, maka rendahnya kinerja perusahaan jasa konstruksi di Provinsi Jambi disebabkan oleh relatif rendahnya kinerja tenaga ahli.

Banyak faktor yang menyebabkan rendahnya kinerja pegawai, menurut hasil penelitian dari Jamil and Sarfaraz (2011: 910) menyatakan bahwa "The compensation practices are positively and significantly associated with employee performance of public sector organizations". Dalam penelitiannya Jamil and

\footnotetext{
${ }^{1}$ Dosen Fakultas Ekonomi Universitas Batanghari
} 
Sarfaraz menyatakan pula bahwa tujuan dasar dari setiap organisasi publik adalah untuk mengkompensasi karyawan dalam setiap cara yang mungkin. Sehingga akibatnya organisasi publik yang diluncurkan untuk menciptakan lapangan kerja. Orang yang memiliki gelar atau keahlian dalam satu bidang dan dapat bekerja di bidang lain karena alasan yang berbeda. Oleh karena itu kompensasi adalah entitas utama yang mempengaruhi kinerja karyawan.

Berdasarkan kedua hasil penelitian di atas, maka rendahnya kinerja tenaga ahli perusahaan jasa konstruksi di Provinsi Jambi cenderung disebabkan oleh masih relatif rendahnya kompensasi tenaga ahli pada perusahaan jasa konstruksi.

Penyebab lainnya berdasarkan penelitian yang dilakukan oleh Ismail and Zainal (2010: 25) pada perusahaan jasa go public di Malayasia, menyatakan bahwa 'the workers' competence has significant influence towards workers' performance, besides that human capital and workers' characteristics also determine workers' performance in the service sector". Bahwa kompetensi pekerja memiliki pengaruh yang signifikan terhadap kinerja pekerja, selain itu sumber daya manusia dan karakteristik pekerja juga menentukan kinerja pekerja di sektor jasa swasta Malaysia. Kemudian June and Mahmood (2011: 88) dalam penelitian pada perusahaan jasa UKM, menyatakan bahwa "that there is significant relationship between role ambiguity, competency and person job fit with the job performance of employees working in the service sector SMEs". Hal ini menunjukkan bahwa ada hubungan yang signifikan antara peran ambiguitas, kompetensi dan job fit pegawai dengan prestasi kerja karyawan yang bekerja di UKM sektor jasa. Sehingga faktor lain yang menyebabkan rendahnya kinerja tenaga ahli kontruksi di Provinsi Jambi, cenderung disebabkan oleh masih relatif rendahnya kompetensi tenaga ahli. Hal ini diindikasikan oleh Sumber Daya Manusia (SDM) jasa konstruksi masih menghadapi permasalahan pada proses sertifikasi yang masih kurang obyektif, sehingga langsung atau tidak langsung menyebabkan tenaga ahli dan tenaga terampil bidang konstruksi masih jauh dari cukup yang di antaranya disebabkan oleh pelaksanaan assessment sertifikasi belum sesuai ketentuan Standar Kompetensi Kerja Nasional Indonesia (SKKNI) (LPJKN, 2012). Namun di sisi lain, SDM konstruksi masih menghadapi kendala lemahnya pembinaan kompetensi yang menyebabkan kualitas dan kuantitas tenaga kerja konstruksi yang bekerja di Indonesia masih jauh dari yang diharapkan. Sementara semakin meningkatnya nilai investasi sektor konstruksi dari tahun ketahun, maka kebutuhan akan tenaga kerja konstruksi yang kompeten dan berdaya saing juga akan semakin besar. Berdasarkan pada data LPJK Provinsi Jambi sampai akhir tahun 2016 Tenaga Ahli yang terigistrasi di LPJK Provinsi Jambi berjumlah 1.321 orang, sementara jumlah Badan Usaha mencapai 3.047 perusahaan.

Mguqulwa (2008: 72) mengemukakan berdasarkan hasil penelitiannya bahwa komitmen organisasi memiliki keterkaitan yang erat dengan kinerja pegawai, yaitu semakin kuat komitmen organisasi, maka kinerja pegawai semakin meningkat. Kemudian hasil penelitiaan Memari, Mahdieh and Barati (2013: 164) menyatakan bahwa "the results revealed a positive relationship between organizational commitment and employees' job performance”. Berdasarkan pernyataan hasil penelitian tersebut, maka rendahnya kinerja tenaga ahli pada perusahaan jasa konstruksi di Provinsi Jambi cenderung disebabkan oleh masih rendahnya komitmen organisasi. Hal ini diindikasikan berdasarkan pada hasil 
observasi peneliti (2015) pada beberapa perusahaan jasa konstruksi yang teregistrasi pada LPJK Provinsi Jambi diperoleh bahwa masih tingginya rata-rata tingkat turn over tenaga ahli (enginner) pertahun pada perusahaan jasa konstruksi.

\section{Kompensasi}

\section{TINJAUAN TEORI}

Dessler (2005) mendefinisikan kompensasi adalah "compensation as all forms of payments or rewards given to employees which arise from their employment". Kompensasi adalah sebagai segala bentuk pembayaran atau imbalan yang diberikan kepada karyawan yang timbul dari pekerjaan mereka. Sehingga kompensasi merupakan salah satu alasan dasar bagi karyawan untuk mencari pekerjaan.

Bernardin dan Russel (2003: 445) kompensasi merupakan "direct Compensation is the basic wage and salaries, plus performance based pay. Indirect compensation programs health insurance, pay for time not worked and various other employee benefits".Demikian juga dengan Mathis dan Jackson (2002: 119) berpendapat, bahwa pada dasarnya kompensasi dapat dikelompokkan dalam dua kelompok, yaitu kompensasi langsung dan kompensasi tidak langsung. Selanjutnya kompensasi langsung terdiri dari gaji pokok dan gaji variabel. Sedangkan kompensasi tidak langsung berupa tunjangan.

\section{Kompetensi}

Francoise and Winterton (2005) "explain that ability is competence that is an unclear concept that touches on knowledge and skills and various elements that are important". Sehingga Francoise and Winterton melihat bahwa kerangka kompetensi berdasarkan satu dimensi tidak cukup dan menyarankan multi dimensi. Sehingga kompetensi merupakan gabungan karakteristik dari tenaga ahli yang memiliki kontribusi meningkatkan kinerja dalam mencapai tujuan organisasi yang telah ditetapkan. Dimensi kompetensi mengacu pada Francoise and Winterton meliputi dari kompetensi kognitif, kompetensi fungsional dan kompetensi sosial.

\section{Komitmen Organisasi}

Meyer dan Allen, dalam Coetzee (2005) menyatakan terdapat tiga dimensi komitmen organisasional, yaitu:

a. Affective commitment, the employee's emotional attachment to, identification with, and involvement in the organization.

b. Continuance commitment, an awareness of the costs associated with leaving the organization.

c. Normative commitment, a feeling of obligation to continue employment.

\section{Kinerja Tenaga Ahli}

Mangkunegara (2007: 67) mendifinisikan "kinerja (performance) adalah hasil kerja secara kualitas dan kuantitas yang dicapai seorang pegawai dalam melaksanakan tugasnya sesuai dengan tanggung jawab yang diberikan kepadanya". Siagian (2008: 94) mendefinisikan kinerja pegawai sebagai suatu hasil kerja yang dicapai seseorang dalam melaksanakan tugas-tugas yang dibebankan kepadanya didasarkan atas kecakapan, pengalaman, kesungguhan serta waktu. Sehingga kinerja pegawai merupakan hasil kerja maksimal yang dicapai oleh pegawai dalam melaksanakan pekerjaannya yang didasarkan atas kecakapan, pengalaman dan kesungguhan serta waktu. Mangkunegara 
(2007:75) menyatakan mengenai empat faktor kinerja pegawai sebagai standar penilaian kinerja, yaitu Kualitas kerja, Kuantitas kerja, Keandalan, dan Sikap.

KERANGKA PEMIKIRAN

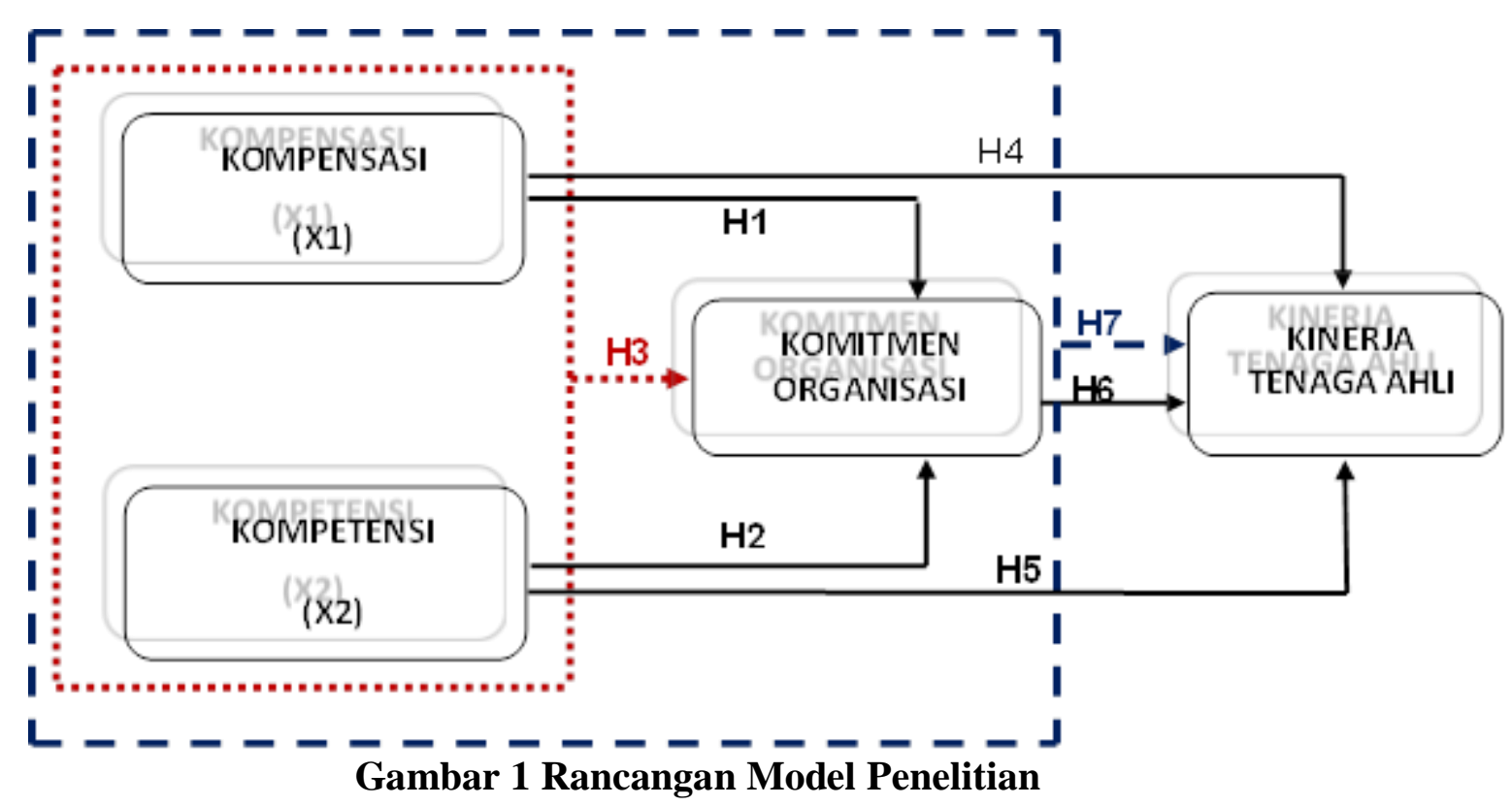

\section{Hipotesis Penelitian}

Berdasarkan kerangka pemikiran di atas dapat di susun hipotesis penelitian sebagai berikut:

1. Terdapat pengaruh kompensasi tenaga ahli terhadap komitmen organisasi pada perusahaan jasa konstruksi di Provinsi Jambi

2. Terdapat pengaruh kompetensi tenaga ahli terhadap komitmen organisasi pada perusahaan jasa konstruksi di Provinsi Jambi.

3. Terdapat pengaruh kompensasi tenaga ahli dan kompetensi tenaga ahli secara bersama-sama terhadap komitmen organisasi pada perusahaan jasa konstruksi di Provinsi Jambi

4. Terdapat pengaruh kompensasi tenaga ahli terhadap kinerja tenaga ahli pada perusahaan jasa konstruksi di Provinsi Jambi

5. Terdapat pengaruh kompetensi tenaga ahli terhadap kinerja tenaga ahli pada perusahaan jasa konstruksi di Provinsi Jambi

6. Terdapat pengaruh komitmen organisasi terhadap kinerja tenaga ahli pada perusahaan jasa konstruksi di Provinsi Jambi

7. Terdapat pengaruh kompensasi tenaga ahli, kompetensi tenaga ahli dan dan komitmen organisasi secara bersama-sama terhadap kinerja tenaga ahli pada perusahaan jasa konstruksi di Provinsi Jambi

\section{METODE PENELITIAN}

Objek penelitian yang menjadi variabel bebas dalam penelitian ini adalah Kompensasi dan Kompetensi. Sedangkan yang menjadi variabel terikat adalah Komitmen Organisasi dan Kinerja Tenaga Ahli. Sifat penelitian ini adalah bersifat deskriptif dan verifikatif. Mengingat sifat penelitian ini adalah deskriptif dan verifikatif yang dilaksanakan melalui pengumpulan data di lapangan, maka 
metode penelitian yang digunakan adalah metode descriptive survey dan metode explanatory survey. Unit analisis dalam penelitian ini adalah para tenaga ahli pada perusahaan jasa konstruksi di Provinsi Jambi yang telah terdaftar di Lembaga Pengembangan Jasa Konstruksi (LPJK) Provinsi Jambi.

\section{Teknik Pengumpulan Data}

Penelitian ini merupakan penelitian persepsi/opini dari objek penelitian, yang dalam hal ini adalah para tenaga ahli perusahaan jasa konstruksi di Provinsi Jambi, oleh karenanya jenis data dalam penelitian ini adalah data subjek (selfreport data), dengan demikian data penelitian diperoleh langsung dari sumbernya yaitu (data primer) dan data sekunder untuk data pendukung. Sedangkan sumber data, yaitu (1) Sumber data sekunder adalah dari perusahaan jasa konstruksi yang terdaftar di Provinsi Jambi, dan (2) Sumber data primer yaitu para tenaga ahli pada perusahaan jasa konstruksi di Provinsi Jambi yang telah terdaftar di Lembaga Pengembangan Jasa Konstruksi (LPJK) Provinsi Jambi.

\section{Populasi dan Sampel}

Ukuran populasi adalah para tenaga ahli anggota dari asosiasi profesi yang telah memiliki sertifikasi dari setiap perusahaan jasa konstruksi yang teregistrasi di LPJK Provinsi Jambi dengan jumlah 1.321 Tenaga Ahli.

Dalam penelitian ini terdapat 4 variabel sehingga diperlukan ukuran sampel minimum sebesar 200 tenaga ahli. Dengan mempertimbangkan terdapatnya data outliers (Hair et al, 2006: 303) dan prinsip semakin besar ukuran sampel semakin baik. Maka besar minimum ukuran sampel dalam penelitian ini dengan menggunakan rasio 1:5, yaitu 5 responden untuk setiap parameter dalam penelitian (Hair et al, 2006: 605). Penelitian ini memiliki 53 parameter (indikator) maka diperoleh ukuran sampel minimum sebesar:

$$
\begin{aligned}
& \mathrm{n}=\text { jumlah parameter } \times 5 \\
& =53 \times 5 \\
& =265 \text { responden }
\end{aligned}
$$

\section{Rancangan Analisis dan Uji Hipotesis}

Berpegang pada pedoman tersebut, serta konvensi dapat dikemukakan tiga persamaan umum dalam SEM. Untuk menguji model SEM dapat dilakukan melalui pendekatan dua tahap, yaitu menguji model pengukuran dan setelah itu menguji model pengukuran dan struktural secara simultan.

Dalam metode analisis SEM, statistik yang estimasi diuji secara individual dengan menggunakan uji t. Melalui keluaran diagram jalur (PTH) statistik $t$-value, Lisrel mengkonfirmasikan hasil uji t secara lengkap dengan tingkat kesalahan uji ditetapkan sebesar 0,05. jika hasil uji menunjukkan nonsignifikai, Lisrel akan mencetak keluaran tersebut dengan sebuah garis diagram jalur berwarna merah. 


\section{HASIL PENELITIAN DAN PEMBAHASAN \\ Hasil Analisis dan Pengujian Hipotesis}

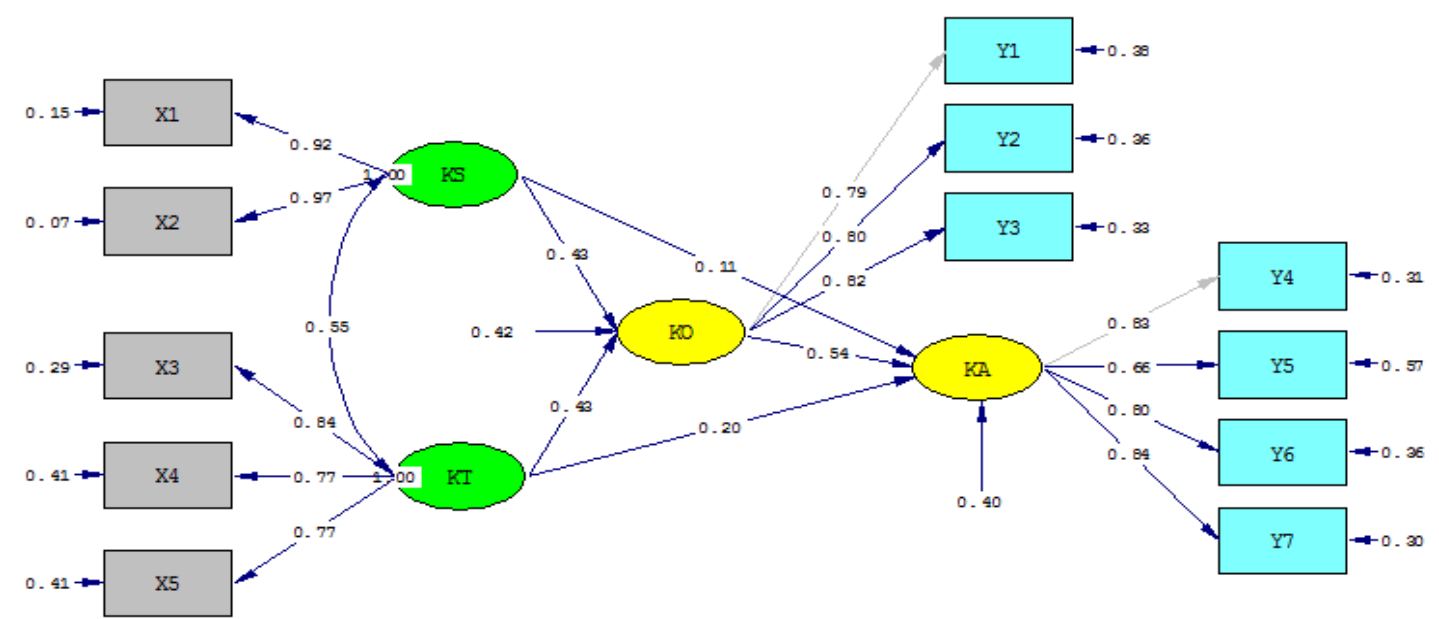

Chi-3quare $=245.45, d f=48, P-v a l u e=0.00000$, RMSEA $=0.085$

Gambar 2. Hybrid Model (Basic Model) Standardized Model

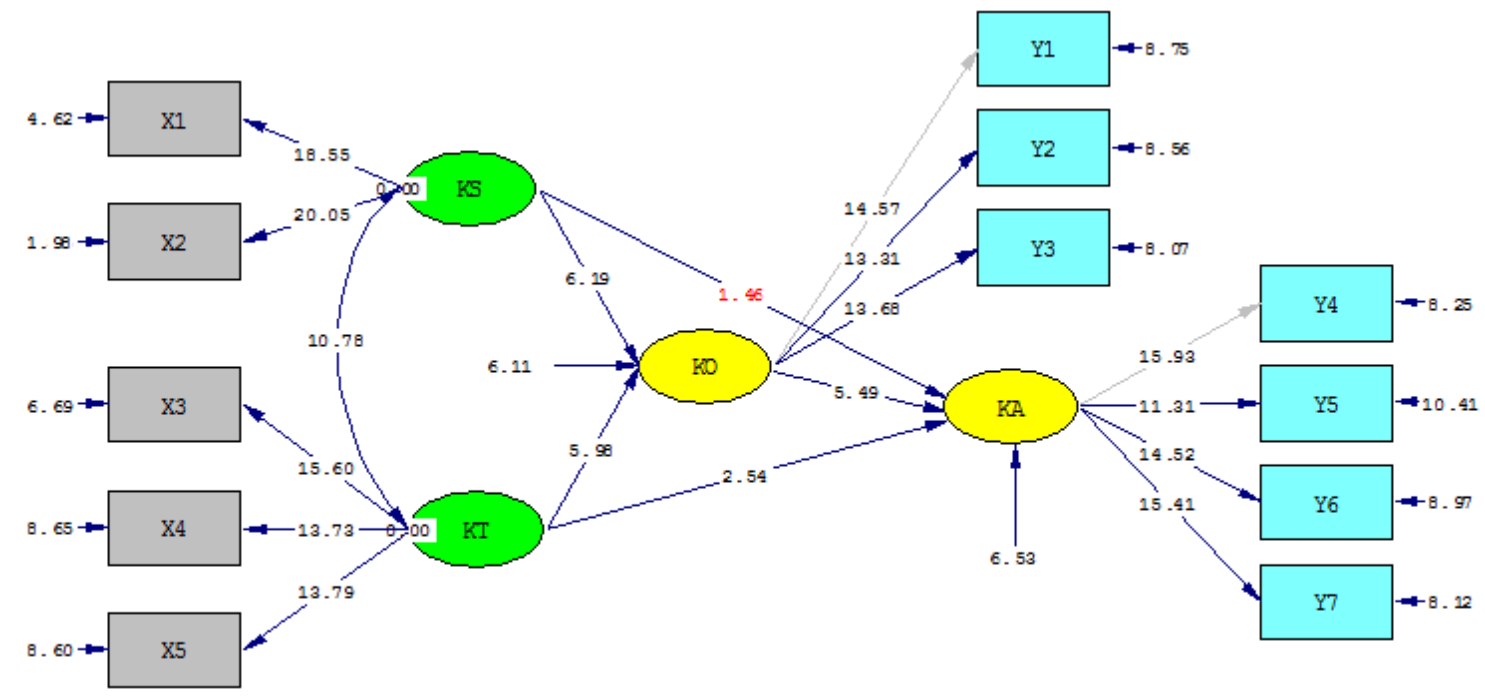

Chi-9quare $=245.45, d f=48, P-v a l u e=0.00000, R M S E A=0.085$

Gambar 3. Hybrid Model (Basic Model) t-Model

Gambar 2 dan Gambar 3 di atas menggambarkan model full SEM.

Hasil pengujian diperoleh kesimpulan bahwa hipotesis dari ketujuh hipotesis penelitian ternyata hanya hipotesis kedua $(\mathrm{H} 2)$ yang tidak diterima (ditolak), sementara enam hipotesis lainnya diterima.

\section{Pengujian Hipotesis}

Dari hasil pengujian hipotesis di atas, maka besar pengaruh langsung dan tidak langsung Kompensasi dan Kompetensi terhadap Komitmen Organisasi pada Tenaga Ahli Perusahaan Jasa Konstruksi di Provinsi Jambi adalah sebagai berikut: 
Tabel 1. Hasil Perhitungan Besar Pengaruh Langsung dan Tidak Langsung Kompensasi (KS) dan Kompetensi (KT) terhadap

Komitmen Organisasi (KO)

\begin{tabular}{lcccc}
\hline \multicolumn{1}{c}{ Variabel } & \multicolumn{2}{c}{ Besar Pengaruh } \\
& Langsung & Tidak Langsung & Ket. & Total \\
\hline $\begin{array}{l}\text { Kompensasi } \\
\text { (KS) }\end{array}$ & 0.1849 & 0.0777 & melaliu KT & 0.2626 \\
Kompetensi & & & \\
(KT) & 0.1849 & 0.0777 & melalui KS & 0.2626 \\
& & $R^{2}{ }_{K S T}$ & $\mathbf{0 . 5 2 5 2}$ \\
\begin{tabular}{l} 
Pengaruh Secara bersama-sama KS, KT terhadap KO \\
\multicolumn{2}{l}{ Pengaruh Variabel luar terhadap KO }
\end{tabular} & $\zeta_{1}$ & 0.4748 \\
\hline
\end{tabular}

Sumber : Hasil Pengolahan Data, 2017 (LISREL 8.80)

Tabel 1 di atas menjelaskan, Pengaruh secara bersama-sama Kompensasi (KS) dan Kompetensi (KT) terhadap Komitmen Organisasi $(\mathrm{KO})$ adalah $0.5252 \approx$ 0.53 atau merupakan $\mathrm{R}^{2}=0.53$

Tabel 2. Hasil Perhitungan Besar Pengaruh Langsung dan Tidak Langsung Kompensasi (KS), Kompetensi dan Komitmen Organisasi (KO) terhadap Kinerja Tenaga Ahli (KA)

\begin{tabular}{|c|c|c|c|c|}
\hline \multirow[t]{2}{*}{ Variabel } & \multicolumn{4}{|c|}{ Besar Pengaruh } \\
\hline & Langsung & Tidak Langsung & Ket. & Total \\
\hline $\begin{array}{l}\text { Kompensasi } \\
(\mathrm{KS})\end{array}$ & 0.0121 & $\begin{array}{l}0.0092 \\
0.0327\end{array}$ & $\begin{array}{l}\text { melalui KT } \\
\text { melalui KO }\end{array}$ & 0.0540 \\
\hline $\begin{array}{l}\text { Kompetensi } \\
\text { (KT) }\end{array}$ & 0.040 & $\begin{array}{l}0.0092 \\
0.0454\end{array}$ & $\begin{array}{l}\text { melalui KS } \\
\text { melalui KO }\end{array}$ & 0.0946 \\
\hline $\begin{array}{l}\text { Komitmen } \\
\text { Organisasi (KO) }\end{array}$ & 0.2916 & $\begin{array}{l}0.0327 \\
0.0454\end{array}$ & $\begin{array}{l}\text { melalui KS } \\
\text { melalui KT }\end{array}$ & 0.3697 \\
\hline $\begin{array}{r}\text { Pengaruh Secar } \\
\text { Pengaru }\end{array}$ & $\begin{array}{l}\text { ersama-sam } \\
\text { Variabel lua }\end{array}$ & $\begin{array}{l}\text {, KT terhadap KO } \\
\text { hadap KO }\end{array}$ & $\begin{array}{c}R^{2} \text { KSKTKO } \\
\zeta_{2}\end{array}$ & $\begin{array}{l}0.5183 \\
0.4817\end{array}$ \\
\hline
\end{tabular}

Sumber : Hasil Pengolahan Data, 2017 (LISREL 8.80)

Tabel 2. di atas menjelaskan, Pengaruh secara bersama-sama Kompensasi (KS), Kompetensi (KT) dan Komitmen Organisasi (KO) terhadap Kinerja Tenaga Ahli (KA) adalah $0.5183 \approx 0.52$ atau merupakan $\mathrm{R}^{2}=0.52$

Hasil pengujian di atas menunjukkan bahwa variabel Kompensasi dan Kompetensi berpengaruh terhadap variabel komitmen organisasi dengan kontribusi sebesar 53\%. Kemudian variabel Kompensasi dan Kompetensi berpengaruh terhadap variabel Kinerja Tenaga Ahli dengan kontribusi sebesar $14,86 \%$. Namun dengan melalui komitmen organisasi, variabel Kompensasi dan Kompetensi berpengaruh terhadap Kinerja Tenaga Ahli dengan kontribusi sebesar 
52\%. Hal ini menunjukkan bahwan Komitmen Organisasi merupakan partial mediating variabel Kompetensi terhadap Kinerja Tenaga Ahli dan no mediating variabel kompensasi terhadap kinerja tenaga ahli pada Perusahaan Jasa Konstruksi di Provinsi Jambi.

Sehingga berdasarkan pengujian hipotesis-hipotesis di atas, maka untuk meningkatkan Kinerja Tenaga Ahli Perusahaan Jasa Konstruksi di Provinsi Jambi terutama pada dimensi kualitas kerja tenaga ahli (Y4) akan mampu ditingkatkan jika Perusahaan Jasa Konstruksi di Provinsi Jambi mampu meningkatkan komitmen organisasi terutama pada dimensi komitmen afektif (Y1), dimana Komitmen Organisasi akan meningkat apabila perusahaan jasa konstruksi mampu meningkatkan Kompetensi terutama pada dimensi kompetensi kognitif (X3) dan mampu meningkatkan kompensasi tenaga ahli terutama pada dimensi kompensasi tidak langsung (X2). Demikian juga Kinerja tenaga ahli Perusahaan Jasa Konstruksi di Provinsi Jambi akan mampu ditingkatkan secara langsung terutama pada dimensi kualitas kerja tenaga ahli (Y4) dengan meningkatkan kompetensi tenaga ahli terutama pada dimensi kompetensi kognitif (X3).

\section{Simpulan}

\section{SIMPULAN DAN SARAN}

1. Kompensasi secara parsial berpengaruh positif dan signifikan terhadap Komitmen Organisasi pada tenaga ahli, artinya bahwa peningkatan Kompensasi tenaga ahli akan mengakibatkan meningkatnya Komitmen Organisasi pada tenaga ahli Perusahaan Jasa Konstruksi di Provinsi Jambi.

2. Kompetensi tenaga ahli secara parsial berpengaruh positif dan signifikan terhadap Komitmen Organisasi, artinya bahwa peningkatan Kompetensi tenaga ahli akan mengakibatkan meningkatnya Komitmen Organisasi pada Tenaga Ahli Perusahaan Jasa Konstruksi di Provinsi Jambi.

3. Kompensasi dan Kompetensi secara bersama-sama berpengaruh positif dan signifikan terhadap Komitmen Organisasi pada tenaga ahli Perusahaan Jasa Konstruksi di Provinsi Jambi dengan nilai koefisien determinasi $\left(\mathrm{R}^{2}\right)$ sebesar 53\%, hal ini menunjukkan bahwa 53\% variabel Komitmen Organisasi mampu dijelaskan secara bersama-sama oleh variabel Kompensasi dan Kompetensi sementara 47\% dipengaruhi variabel selain Kompensasi dan Kompetensi.

4. Kompensasi secara parsial berpengaruh positif dan tidak signifikan terhadap Kinerja Tenaga Ahli.

5. Kompetensi secara parsial berpengaruh positif dan signifikan terhadap Kinerja Tenaga Ahli, artinya bahwa peningkatan Kompetensi tenaga ahli akan mengakibatkan meningkatnya Kinerja Tenaga Ahli Perusahaan Jasa Konstruksi di Provinsi Jambi.

6. Komitmen Organisasi secara parsial berpengaruh positif dan signifikan terhadap Kinerja Tenaga Ahli, artinya bahwa peningkatan Komitmen Organisasi akan mengakibatkan meningkatnya Kinerja Tenaga Ahli perusahaan Jasa Konstruksi di Provinsi Jambi.

7. Kompensasi, Kompetensi dan Komitmen Organisasi secara bersama-sama berpengaruh positif dan signifikan terhadap Kinerja Tenaga Ahli Perusahaan Jasa Konstruksi di Provinsi Jambi dengan nilai koefisien determinasi $\left(\mathrm{R}^{2}\right)$ sebesar 52\%, hal ini menunjukkan bahwa 52\% variabel Kinerja Tenaga Ahli mampu dijelaskan secara bersama-sama oleh variabel Kompensasi, 
Kompetensi dan Komitmen Organisasi sementara 48\% dipengaruhi variabel lain.

8. Untuk meningkatkan Kinerja Tenaga Ahli Perusahaan Jasa Konstruksi di Provinsi Jambi terutama pada dimensi kualitas kerja tenaga ahli (Y4) akan mampu ditingkatkan jika Perusahaan Jasa Konstruksi di Provinsi Jambi mampu meningkatkan komitmen organisasi terutama pada dimensi komitmen afektif (Y1), dimana Komitmen Organisasi akan meningkat apabila perusahaan jasa konstruksi mampu meningkatkan Kompetensi terutama pada dimensi kompetensi kognitif (X3) dan mampu meningkatkan kompensasi tenaga ahli terutama pada dimensi kompensasi tidak langsung (X2). Demikian juga Kinerja tenaga ahli Perusahaan Jasa Konstruksi di Provinsi Jambi akan mampu ditingkatkan secara langsung terutama pada dimensi kualitas kerja tenaga ahli (Y4) dengan meningkatkan kompetensi tenaga ahli terutama pada dimensi kompetensi kognitif (X3).

\section{Saran}

1. Masih banyak variabel lain yang mempengaruhi Kinerja Tenaga Ahli pada Perusahaan Jasa Konstruksi di Provinsi Jambi, seperti disiplin kerja, keterikatan kerja, motivasi, kepuasan, pemberdayaan, kepemimpinan, kemampuan manajerial dan variabel lainnya agar diteliti lebih lanjut, karena mungkin saja ada variabel-variabel lain selain yang ada pada penelitian ini memiliki pengaruh dominan dalam meningkatkan Kinerja Tenaga Ahli.

2. Penelitian ini menggunkan variabel Komitmen Organisasi sebagai variabel antara (intervening), sehingga untuk penelitian selanjutnya kemungkinan akan menghasilkan temuan yang berbeda apabila menggunakan variabel lain atau menempatkan variabel Komitmen Organisasi sebagai variabel moderasi (moderating).

3. Hasil penelitian ini dapat juga diterapkan pada perusahaan, lembaga atau instansi pemerintah, badan usaha milik negara atau swasta baik tingkat provinsi maupun nasional.

\section{DAFTAR PUSTAKA}

Afshan, Sultana et al, 2012. "Impcat of Training on Employee Performance": A Study of Telecommunication Sector in Pakistan. Indiciplinary Journal of Contemporary Research in Business, Vol 4, No. 6

Awadh, Alharbi Mand Saad, Alyahya M. 2013. "Impact of Organizational Culture on Employee Performance". International Review of Management and Business Research. Vol. 2 Issue. 1

Bernadin, H. John and Russell, Joyce E, A, 2003, "Human Resource Management: an Experimental Approach", Singapore: McGraw-Hill Book Co.

Cascio, W. F. 2006. "Managing Human Resources: Productivity, Quality of Life, Profits". London McGraw-Hill Irwin.

Coetzee, M. 2005. "Employee Commitment". University of Pretoria etd. http://upetd.up.ac.za/available/etd04132005130646/unrestricted/05chapter $\underline{\text { 5.pdf. }}$

Dessler, Gary. 2005, "Human Resource Management", Tenth Edition, New Jersey: Prentice Hall. 
Francoise, Delamare Le Deist, \& Jonathan, Winterton. 2005. "What Is Competence?". Human Resources Development International,Vol. 8, No. 1, 27 - 46, March 2005

Hair et al., 2006, "Multivariate Data Analysis", Fifth Edition, New Jersey. Prentice Hall, Upper Saddle River.

Ismail, Rahmah and Zainal, Syahida A. 2010. "Impact of workers' competence on their performance in the Malaysian private service sector". Journal Business and Economic Horizons, ISSN: 1804-1205, Volume 2, Issue 2, July 2010, pp. 25-36

Jamil, Bilal and Sarfaraz, Naintara Raja. 2011. "Impact of Compensation, Performance Evaluation and Promotion Practices on Government Employees Performance VS Private Employees Performance". Interdisciplinary Journal of Contemporary Research In Business December, Vol 3, No 8

Jöreskog, Karl G. and Dag Sörbom. 2001. “LISREL 8: User's Reference Guide”. Lincoln wood, IL: Scientific Software International, Inc.

June, Sethela and Mahmood, Rosli. 2011. "The Relationship between Role Ambiguity, Competency and Person-Job Fit With the Job Performance of Employees in the Service Sector SMEs in Malaysia". Business Management Dynamics, Vol.1, No.2, August 2011, pp.79-98

Kementerian PU. 2013. "Perkembangan Standar Kompetensi Kerja Nasional Indonesia (SKKNI) Jasa Konstruksi" Jakarta. Edisi II. Buletin Badan Pembinaan Konstruksi. ISSN 1907-0136

LPJK Nasional. 2013. "Panduan Pelatihan Asesmen" Palembang. Lembaga Pengembangan Jasa Konstruksi.

LPJK Provinsi. 2012. “Laporan Akhir Tahun”, Jambi. Lembaga Pengembangan Jasa Konstruksi.

Mangkunegara, Anwar Prabu. 2007. "Evaluasi Kinerja Sumber Daya Manusia". Bandung: PT.Refika Aditama

Mathis, RL and Jackson, JH. 2002. “Manajemen Sumber Daya Manusia”. Buku I. Jakarta. PT. Salemba Emban Patria.

Mguqulwa, Nomakhuze. 2008. "The Ralatonships Between Organisational Commitment and Work Performance in an Agricultural Company" Universityof South Africa. Industrial and Organisational Psychology.

Siagian, Sondang P., 2008, "Manajemen Sumber Daya Manusia”, Jakarta cetakan ketujuh: Penerbit Radar Jaya Offset.

Sugiyono, 2013, "Statistika untuk Penelitian”, Bandung. Alfa Beta.

Suharsimi, Arikunto, 2002, "Prosedur Penelitian Suatu Pendekatan Praktek", Jakarta: Rineka Cipta.

Supanto J, Nandan Limakrisna. 2012. "Petunjuk Praktis Penelitian Ilmiah untuk menyusun Skripsi, Tesis dan Disertasi” Jakarta. Penerbit Mitra Wacana Media.

Wijanto. 2008. "Sructural Equation Modeling dengan Lisrel 8.8”. Jakarta, Pasca Sarjana Ilmu Manajemen Fakultas Ekonomi UI. 